\title{
Influence of Calcium Carbonate and Slip Agent Addition on Linear Medium Density Polyethylene Processed by Rotational Molding
}

\author{
Marina I. Baumer, Janaina L. Leite ${ }^{\text {a }}$ Daniela Becker ${ }^{\text {b* }}$ \\ ${ }^{\mathrm{a}}$ Educacional Society of Santa Catarina - SOCIESC, Joinville, SC, Brazil \\ ${ }^{\mathrm{b}}$ Center for Technological Sciences, State University of Santa Catarina - UDESC, Joinville, SC, Brazil
}

Received: January 28, 2013; Revised: August 27, 2013

\begin{abstract}
In this paper, the influence of calcium carbonate and slip agent on linear medium density polyethylene (LMDPE) processed by rotational molding was evaluated. LMDPE was dry blended with different $\mathrm{CaCO}_{3}$ masterbatch ratios, erucamide slip agent and then extruded, micronized and rotomolded. The powder samples were characterized using MFI (Melting flow index), dry flow and bulk density. The characterization of rotomolded samples properties was performed by DSC (Differential scanning calorimetry), microscopy analysis, izod impact and tensile test. The results pointed out that the $\mathrm{CaCO}_{3}$ addition modifies the bulk density compared to neat LMDPE, but did not significantly affect the dry flow and MFI. The erucamide addition decreased the dry flow and increased the bulk densities. The porosity degree data showed that $\mathrm{CaCO}_{3}$ addition in the LMDPE increased the quantity of pores. The DSC results showed no significant difference in the crystallinity degree. The behavior of porosity led to a decrease in the mechanical properties of LMDPE with the $\mathrm{CaCO}_{3}$ addition.
\end{abstract}

Keywords: rotational molding, calcium carbonate, linear medium density polyethylene

\section{Introduction}

Rotational molding is a method for manufacturing hollow or open plastic articles in many different shapes and sizes. Rotational molding involves powder mixing, melting, sintering, and melting solidification. One of the great advantages of rotational molding is the low cost and the simplicity of mold, because the molten polymer takes the shape of the mold under very low stresses ${ }^{1,2}$. The principal polymer used in rotational molding is polyethylene, due to its high thermal stability and the wide range of grades developed for this process ${ }^{3-5}$. Hafsaoui et al. ${ }^{6}$ affirm that the principal disadvantage of rotational molding is the relatively long cycle time compared to conventional techniques and they present a thermal model for simulation which permits to follow the local evolution of the temperature in various areas of rotational molding and gives a good representation of experimental data. Monzón et al. ${ }^{7}$ proposed a modified mold where it was directly heated by oil. The studies with the prototype showed a reduction in cycle time $(50 \%)$. Other disadvantage is the presence of air bubbles in the material that reduces the mechanical properties and the surface quality of the final product part ${ }^{8}$. Asgarpour et al. ${ }^{8}$ using a three-dimension model for the densification of a powder compact during rotational molding observed that factors as power particle size and packing arrangement controlled the initial bubble size, the polymer properties (surface tension and viscosity) affect the densification rate, molding condition and polymer properties (surface tension and viscosity) influence in the bubble life time. High surface tension and temperature increase the diffusivity of gas into the polymer and decrease bubble life time.

*e-mail: dep2db@joinville.udesc.br
Beyond performance, industry has a necessity for materials that increase performance and/or reduce cost of their products to become more competitive in the market. Yan et al. ${ }^{4}$ mention that the rotational molding industry is progressing rapidly with growth rate of $10-20 \%$ per annum, thus research has been carried out in order to improve the process efficiency and product quality in rotational molding.

Studies related to the addition of fillers in polymers for rotational molding, such as glass fibers, natural fibers, graphite and calcium carbonate has been evaluated because it is a fast and cheap method to modify the properties of the matrix material ${ }^{4,9-13}$. López-Bañuelos et al. ${ }^{12}$ studied the properties of agave fibers/polyethylene composistes manufactured by rotational molding. They observed that $10 \%$ of fiber was an optimum fiber concentration due to the difficulty to the matrix wet all fibers during rotational molding process. The introduction of fillers in polymers, such as calcium carbonate, is increasing interest because this material has both good performance and low $\operatorname{cost}^{14}$. Harkin-Jones and Kanokboriboon ${ }^{11}$ investigated the ability of nano-scale calcium carbonate $\left(\mathrm{nm}-\mathrm{CaCO}_{3}\right)$ to improve the impact strength of rotationally moulded polypropylene parts. González et al. ${ }^{15}$ evaluated the effects of coupling agents on mechanical and morphological behavior of the PP/HDPE blend with two different $\mathrm{CaCO}_{3}$. Thio et al. ${ }^{16}$ investigated the thoughening of isotatic polypropylene with $\mathrm{CaCO}_{3}$ particles and observed the addition of fillers (in slow tension) decrease the yield stress and increase de modulus.

Besides the addition of fillers, the distribution of fillers has a great influence on the viscoelasticity of the polymer matrix, which can be improved by the addition of dispersants 
or slip agents. These additives reduce the viscosity of the matrix and prevent the fillers from forming cluster or network, besides improving processing, the characteristics of the surface and the final properties and lifetime of polymer materials ${ }^{17-19}$. Browning et al. ${ }^{18}$ evaluated the effects of slip agent and talc surface-treatment on the scratch behavior of thermoplastics olefins and pointed out that these additives tend to exhibit prolonged ductile drawing and increase the load require to initiate scratch visibility. Chaudhary ${ }^{20}$ used low molecular weight additives as sintering enhancers in rotational molding and they observed a reduction in melt viscosity, besides faster densification and bubble removal were also observed. Kulikov et al. ${ }^{21}$ evaluated a novel processing additives for rotational moulding of polyethylene and observed that the additives as silica fume, vinyl-silanes and stearates improve the flowability of PE micro-pellets during the rotomoulding process. The present contribution focuses on evaluate the influence of calcium carbonate with and without slip agent on the porosity and mechanical properties of the linear medium density polyethylene (LMDPE) processed by rotational molding.

\section{Experimental}

\subsection{Materials}

The resin used in this study was linear medium density polyethylene (LMDPE) MR435UV, supplied by Braskem with MFI of 4,0 g/10min and density of $0,934 \mathrm{~g} / \mathrm{cm}^{3}$. In order to add $\mathrm{CaCO}_{3}$ filler to in LMDPE, firstly the $\mathrm{CaCO}_{3}$ was dried in vacuum oven at $60^{\circ} \mathrm{C}$ for $24 \mathrm{~h}$ and masterbatch with the $\mathrm{CaCO}_{3}$ was prepared by the Karina company in the proportion of $80 \% \mathrm{CaCO}_{3}$ and $20 \% \mathrm{LMDPE}$. The average particle size of $\mathrm{CaCO}_{3}$ was $2.0 \mu \mathrm{m}$. The slip agent called erucamide (Crodamide ER Powder - Croda Brazil ) and a blue pigment (supplied by Cristal Master) was used in the composite in the proportion of $0.2 \%$ and $1.0 \%$, respectively.

\subsection{Composite preparation}

LMDPE was dry blended with different $\mathrm{CaCO}_{3}$ masterbatch ratios (2.0, 5.0 and 10.0\%), slip agent and pigment and then extruded using Ciola B-50 single-screw extruder with a pelletizer. The screw length-over-diameter (L/D) was 25/1. The extrusion temperature was around $180{ }^{\circ} \mathrm{C}$. The granules were micronized using an equipament of Tritumaq TM250. Table 1 presents the composites

Table 1. Composites formulations.

\begin{tabular}{lccc}
\hline Composite & $\begin{array}{c}\mathrm{CaCO}_{3} \\
(\boldsymbol{\%})\end{array}$ & $\begin{array}{c}\text { Erucamide } \\
(\boldsymbol{\%})\end{array}$ & $\begin{array}{c}\text { Pigment } \\
(\boldsymbol{\%})\end{array}$ \\
\hline LMDPE00 & LMDPE neat & - & 1.0 \\
LMDPE02 & 1.6 & - & 1.0 \\
LMDPE05 & 4.0 & - & 1.0 \\
LMDPE10 & 8.0 & - & 1.0 \\
LMDPE02A & 1.6 & 0.2 & 1.0 \\
LMDPE05A & 4.0 & 0.2 & 1.0 \\
LMDPE10A & 8.0 & 0.2 & 1.0 \\
\hline
\end{tabular}

obtained, pointing out the final filler proportion in each composite.

\subsection{Specimen fabrication}

The molding of the composites with different compositions was carried out using a rock-and-roll machine with a cylindrical steel mould having a length of $750 \mathrm{~mm}$, a diameter of $1180 \mathrm{~mm}$, and a wall thickness of around $2.5 \mathrm{~mm}$. In this type of machine, the mold rotates through the axis of support arm, and the oven performs a swinging motion (from $45^{\circ}$ to $45^{\circ}$ to the right to the left) perpendicular to the support arm, allowing the spreading of the material for the ends of the piece. The specimens were cut from the cylindrical container walls and machining was done according to the standard methods (Figure 1). The specimens dimension for tensile strength test was $200 \times 130 \times 2 \mathrm{~mm}$ and to impact test was $80 \times 10 \times 2 \mathrm{~mm}$. The rotational molding process parameters are listed in Table 2.

\subsection{Composite characterization}

\subsubsection{Particle size distribution}

The particle size distributions of the composites were carried out according to ASTM D1921 22 . This test determines "percent passing" or "percent retained" for a given sieve. The conditions tested were initial weight $100 \mathrm{~g}$ and time sieving $10 \mathrm{~min}$.

\subsubsection{Melt Flow Index}

The melt flow index (MFI) of the composites were determined according to ISO $1133^{23}$, using a moderated strain-rate of $2.16 \mathrm{~kg}$ of static mass at $190{ }^{\circ} \mathrm{C}$ in a Pantec MFI400E device.

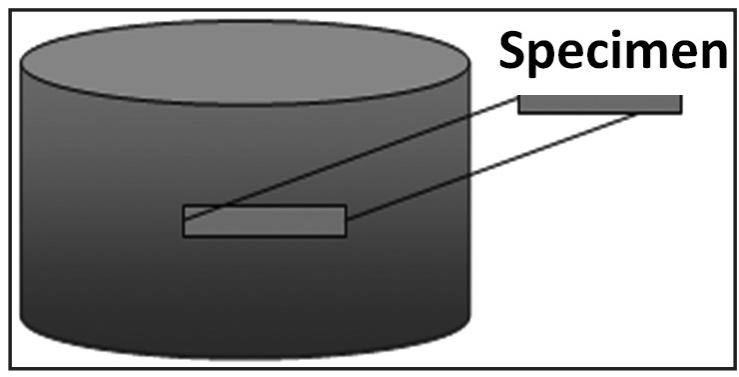

Figure 1. Schematically, the cylindrical container rotomolded and the specimen cut from the walls.

Table 2. Rotomolding process parameters.

\begin{tabular}{lc}
\hline \multicolumn{1}{c}{ Parameters } & Values \\
\hline Mold heating time & $3,6 \mathrm{~min}$ \\
Rotomolding process time & $12 \mathrm{~min}$ \\
Rotomolding process cooling time & $10,3 \mathrm{~min}$ \\
External mold temperature during the material & $150{ }^{\circ} \mathrm{C}$ \\
rotomolding processl & \\
External mold temperature after the cooling process & $45^{\circ} \mathrm{C}$ \\
\hline
\end{tabular}




\subsubsection{Dry flow}

Powder dry flow properties are important during rotational molding as they determine how the polymer distributes itself within the mold and how well the polymer melt flows into complex shapes ${ }^{24}$. The method used to measure this property for the powder composites was based on ASTM D- $1895^{25}$. It is the time taken for $100 \mathrm{~g}$ of powder to flow through a standard funnel. The dry flow is quoted in seconds.

\subsubsection{Bulk density}

Bulk density is a measure of the efficiency with which the powder particles pack together. In order to evaluate the efficiency of the packing of the powder particles, the bulk density was determined by pouring a weighed amount of powder $(40 \mathrm{~g})$ into a standard container to measure its volume. This test was based on ASTM D- $1895^{25}$ and 5 samples were tested.

\subsubsection{Differential Scanning Calorimetry}

Differential scanning calorimetry (DSC) curves for the rotomolded composites were obtained using a differential calorimeter (DSC Q20 TA instruments) from 25 to $300{ }^{\circ} \mathrm{C}$ at a heating rate of $10{ }^{\circ} \mathrm{C} / \mathrm{min}^{-1}$. The average sample size was $5 \mathrm{mg}$ and the nitrogen flow rate was $25 \mathrm{~cm}^{3} \mathrm{~min}^{-1}$. The percent of crystallinity (Xc) was determined from the enthalpy of crystallization of PE, Equation 1, using a value of $\Delta \mathrm{H}_{\mathrm{f}}^{\circ}=293 \mathrm{~J} / \mathrm{g}$ for PE $100 \%{ }^{26}$ crystalline and the enthalpy values were corrected for PE weight present in the composite.

$X_{c}=\left(\frac{\Delta H_{\text {amostra }}^{o}}{\Delta H_{f}^{0}}\right) \times 100$

\subsubsection{Microscopy Analysis}

The pore analysis and the morphology of the rotomolded composites were examined using optical microscopy (OM) and scanning electron microscopy methods (SEM), respectively. The pore analysis of the rotomolded composites surfaces was carried out using an Olympus BX-51 optical microscope with $50 \times$ magnification and phase contrast. The program used to estimate the pore content was Image Pro-Plus ${ }^{\circledR}$. In order to analyze the content, the quantity and average size of the pores were considered. The porosity percentage was calculated according Equation 2. The total area analyzed for each composite was around $113 \mathrm{~mm}^{2}$. The pore analysis was adapted from studies of Spencer and Crawford ${ }^{3}$. These authors have also analyzed the pores in the surface and cross section of the rotomolded parts.

Porosity $(\%)=\sum$ pore area $/ \sum$ analyzed area

The cryogenic fracture surfaces of the rotomolded composites were investigated with a JEOL/JSM 6360 scanning electron microscope.

\subsubsection{Mechanical testing}

Standard tests were conducted at room temperature to determine the mechanical properties, such as tensile strength and IZOD impact strength for the rotomolded composites.
Tensile testing was performed using an elongation velocity of $10 \mathrm{~mm} / \mathrm{min}$ in a universal testing machine EMIC DN 3000 based in ISO $527^{27}$. The force was measured by a load cell of $2000 \mathrm{~N}$ and the displacement recorded by an extensometer and 10 samples was tested.

Izod Impact testing was based in ISO $180^{28}$ with samples thinner than recommend by the standard due to limitation of process. It was performed in the Microstest Impact Tester, and the samples were $\mathrm{V}$-shaped notched (tip radius $0.25 \mathrm{~mm}$, depth $2.0 \mathrm{~mm}$ ) and 15 samples was tested.

\section{Results and Discussion}

\subsection{Powder characterization}

Table 3 presents dry flow and bulk density results. Powder dry flow properties are important during rotational molding as they determine how the polymer distributes itself within the mold and how well the polymer melt flows into complex shapes ${ }^{17}$. Calcium carbonate addition does not significantly modify the dry flow. However, the erucamide (slip agent) addition decreased the dry flow, improving material flowability and suggests that the slip agent decreased the friction coefficient among particles, as pointed out by Quijada-Garrido et $\mathrm{al}^{29}$. No evidences of interaction between the erucamide and $\mathrm{CaCO}_{3}$ was observed in these results.

The bulk density of $\mathrm{CaCO}_{3}$ composites was superior to that of neat PE. The composites without erucamide present an increase of $7 \%$ in bulk density for composites with 2 and $5 \%$ of $\mathrm{CaCO}_{3}$ and $8 \%$ for composites with $10 \%$ of $\mathrm{CaCO}_{3}$ and materials with slip agent present an increase of $10 \%$, $12 \%$ and $15 \%$ in bulk density for composites with $2 \%, 5 \%$ and $10 \%$ respectively. According to Crawford and Throne ${ }^{24}$, bulk density is a measure of the efficiency with which the powder particles pack together and it is dependent on the particle shape, particle size, and particle size distribution of the powder. It was found that there are more particles with smaller sizes in the composites with $\mathrm{CaCO}_{3}$ than neat PE, which can lead to a better packing of the particles, hence its higher bulk density (Table 4). Dry flow and bulk density are inversely related, in that an increase in the bulk density corresponds to a faster dry flow rate ${ }^{24}$. The melt flow index results for all composites were approximately $4.0 \mathrm{~g} / 10 \mathrm{~min}$, showing that the filler proportions and erucamide added do not significantly change the MFI. Some authors ${ }^{30,31}$ also observed that the calcium carbonate can retain the

Table 3. Dry flow and bulk density results.

\begin{tabular}{lcc}
\hline \multicolumn{1}{c}{ Material } & $\begin{array}{c}\text { Dry flow } \\
\mathbf{s} / \mathbf{1 0 0 g}\end{array}$ & $\begin{array}{c}\text { Bulk density } \\
\mathbf{k g} / \mathbf{m}^{\mathbf{3}}\end{array}$ \\
\hline LMDPE00 & $26 \pm 1$ & $390 \pm 5$ \\
LMDPE02 & $25 \pm 2$ & $417 \pm 4$ \\
LMDPE05 & $27 \pm 2$ & $417 \pm 3$ \\
LMDPE10 & $25 \pm 3$ & $423 \pm 4$ \\
LMDPE02A & $18 \pm 3$ & $432 \pm 2$ \\
LMDPE05A & $19 \pm 2$ & $437 \pm 3$ \\
LMDPE10A & $18 \pm 2$ & $450 \pm 4$ \\
\hline
\end{tabular}


MFI value of PP and they suggested that this behavior was related with the ability of $\mathrm{CaCO}_{3}$ to increase the plasticity and processability of the polymer.

The quality of rotationally molded parts depends not only on the physical properties, but also on the characteristics of the powder, such as its shape, size and particle uniformity ${ }^{3}$. According to Galera ${ }^{32}$ and Crawford and Throne ${ }^{24}$ is difficult to define the best particle size distribution. These authors suggested particle size distribution among $150 \mu \mathrm{m}$ to $500 \mu \mathrm{m}$ is quite acceptable in rotational molding, with a maximum of $5 \%$ of particles above $500 \mu \mathrm{m}$, and $15 \%$ below $150 \mu \mathrm{m}$. The excess of coarse particles increases the material melting time, generates a rough surface on the inside of the part and increases the porosity. However, the excess of thinner particles will cause loss of material due to the air suspension and hinder the flowability of the material. Table 4 presents the percentage of large and small composite particle sizes. These results show that all composites had more than 5\% of particles larger than $500 \mu \mathrm{m}$, which can increase the melting time of the material, creating an irregular surface on the inside part and increased porosity ${ }^{33}$.

\subsection{Rotational molded characterization}

Table 5 presents melting temperature (Tm), melting enthalpy $\left(\Delta H_{\text {melt }}\right)$ and percent of crystallinity $\left(\mathrm{X}_{c}\right)$ of composites. It can be noted that addition of $\mathrm{CaCO}_{3}$ does not show any significant difference in melting temperature. The degree of crystallinity for all samples ranges from 36 for neat LMDPE and 30 to 34 for all composites. In this case, we could not affirm that there is significant difference in the crystallinity degree. Tiemprateeb et al. ${ }^{34}$ also observed that cristallinity fo $\mathrm{PE}$ remain comparatively constant for different $\mathrm{CaCO}_{3}$ content. Huang et al. suggested ${ }^{35}$ that microparticles can nucleate because they can provide sufficiently large flat domains, whereas the size of microparticles is comparable to the spherulite size of PE and thus also hinder the spherulite growing, so the degree of crystallinity in microcomposites is not significantly larger than that of the neat LDPE

Figures 2 and 3 illustrate the optical and SEM micrographs of the external surface and the cross section of rotomolded composites, respectively. These micrographs

Table 4. Percentage of large and small composite particle sizes.

\begin{tabular}{lcccccccc}
\hline & Literature & LMDPE & LMDPE02 & LMDPE05 & LMDPE10 & LMDPE02A & LMDPE05A & LMDPE10A \\
\hline$>500 \mu \mathrm{m}$ & Max. 5\% & $5.6 \%$ & $9.0 \%$ & $7.0 \%$ & $8.0 \%$ & $6.2 \%$ & $9.5 \%$ & $7.2 \%$ \\
$<150 \mu \mathrm{m}$ & Máx. 15\% & $4.8 \%$ & $14.1 \%$ & $12.5 \%$ & $14.8 \%$ & $11.1 \%$ & $11.5 \%$ & $13.0 \%$ \\
\hline
\end{tabular}

Table 5. DSC results of rotational molded samples.

\begin{tabular}{cccc}
\hline Material & $\mathbf{T m}\left({ }^{\circ} \mathbf{C}\right)$ & $\Delta \mathbf{H}_{\text {melt }}(\mathbf{J} / \mathbf{g})$ & $\mathbf{X}_{\mathbf{c}}(\boldsymbol{\%})$ \\
\hline LMDPE00 & 119.4 & 141.6 & 36 \\
LMDPE02 & 118.2 & 124.1 & 31 \\
LMDPE05 & 118.8 & 131.4 & 33 \\
LMDPE10 & 119.7 & 118.5 & 30 \\
LMDPE02A & 118.8 & 123.1 & 31 \\
LMDPE05A & 119.5 & 124.2 & 31 \\
LMDPE10A & 118.9 & 134.8 & 34 \\
\hline
\end{tabular}

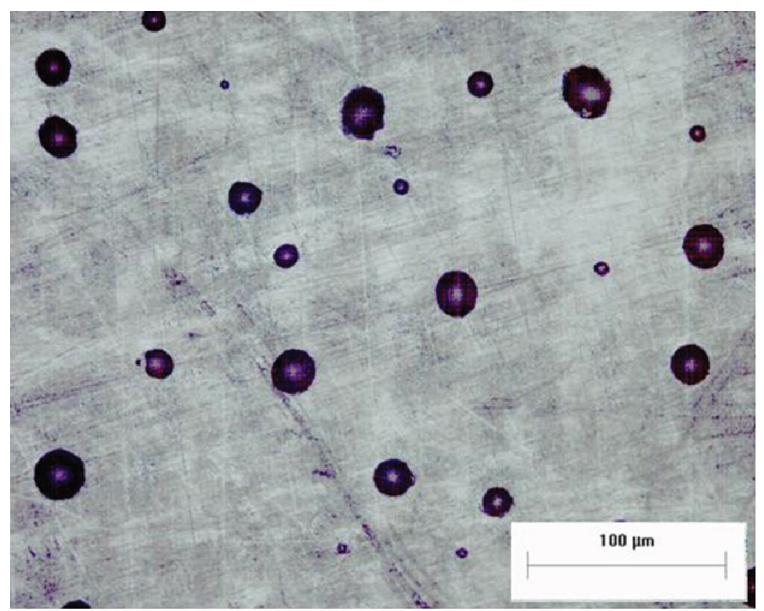

(a)

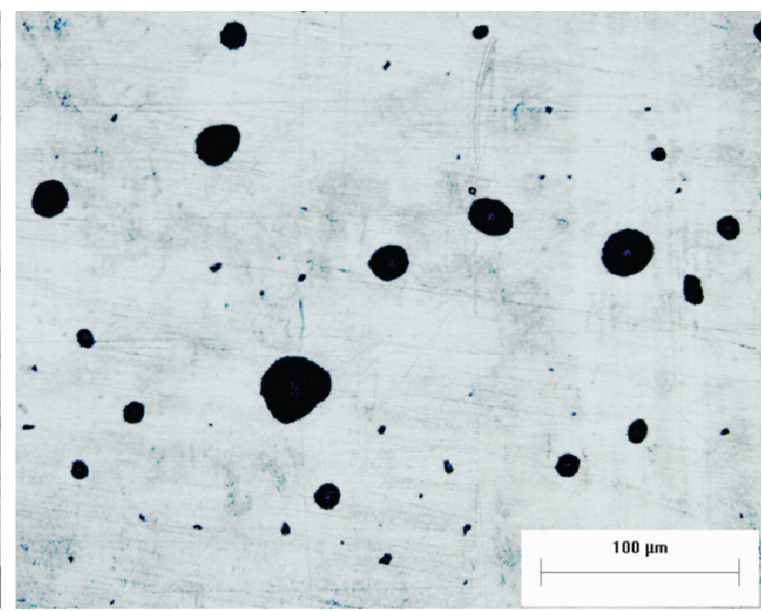

(b)

Figure 2. Optical microscopy of the external surface of rotomolded composite: (a) LMDPE05A and (b) LMDPE10A, with magnification of $50 \times$. 
clearly show the porous presence along the external surface and cross section surface for both composites. The others composites compositions showed similar behavior. The porous presence in both rotomolded composites can be influenced by the particles size, which has more than $5 \%$ of particles larger than $500 \mu \mathrm{m}$ (Table 4) and the viscosity observed in the by MFI analysis results. As mention previously, this percentage of large particles can increase the melting time of the material, creating an irregular surface on the inside part and increased porosity. Referent to MFI, Spence and Crawford ${ }^{3}$ in their studies with rotationally molded products observed that materials with an MFI of less than $5.0 \mathrm{~g} / 10 \mathrm{~min}$ showed a porous surface in the rotomolded samples, and concluded that in longer polymer chains the melt is more viscous and the passage of air bubbles through the melt polymer is more difficult. Both facts indicate that during the rotomolding process there is not sufficient time and temperature for the air bubbles to diffuse out of the polymer melt with MFI of $4.0 \mathrm{~g} / 10 \mathrm{~min}$. According these authors ${ }^{3}$, is recommended as a solution to solve the problems of bubbles in rotomolded parts, to raise the oven temperature, to increase the heating cycle or to use a high melt flow index material.

The porosity analysis results of the surface and fracture cross section of rotomolded composites are shown in Table 6. The cross section porosity for neat LMDPE was not possible to analyze due to its pore sizes being too small.

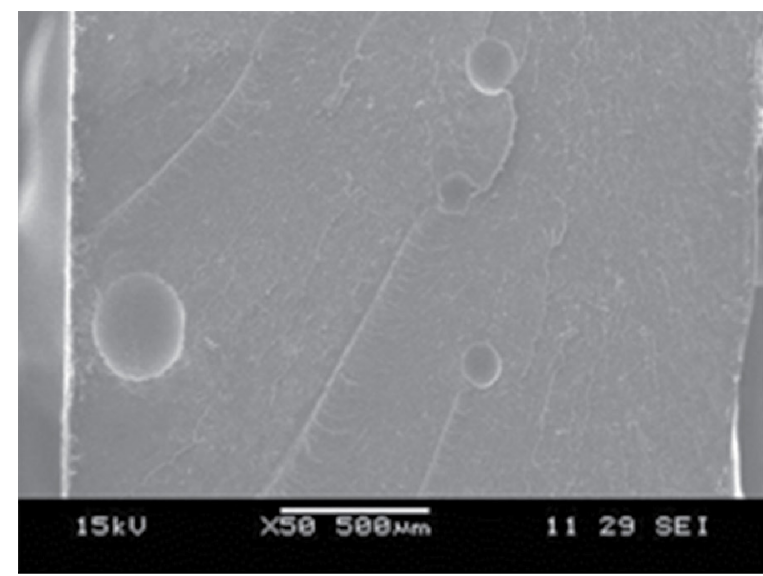

(a)
The composites show that in the cross section the porosity degree increased with the increase in $\mathrm{CaCO}_{3}$ fractions. The composites with superior $\mathrm{CaCO}_{3}$ content present minor average pore size, but higher amount of pore per area $\left(\mathrm{mm}^{2}\right)$, this fact indicate that the filler hinder the diffusion of the bubbles throughout the part. This behavior is not observed in sample LMDPE10A. Spence and Crawford ${ }^{3}$ observed the same behavior with the carbon black addition, they suggested that this filler obstruct and inhibit the passage of air molecules through the polymer melt. The porosity presented by the surface of rotomolded composite shows the opposite behavior compared with the porosity presented by the cross section, indicating again, that the fillers hamper diffusion of air bubbles along the part. The increase of porosity indicates that the material requires longer processing time for the densification process ${ }^{11,36}$.

The fracture surface cross-section of rotomolded composites with the erucamide addition showed, according Table 6, a slight decrease in the porosity related to the rotomolded composites without the additive. This fact suggests that the slip agent reduced the coefficient of friction between the particles, consequently improving the packing particles because less air bubbles will be trapped into the particles, increasing the densification process in these rotomolded composites.

The cryogenic fracture micrographs of the rotomolded composites are shown in Figure 4. The non-adherence

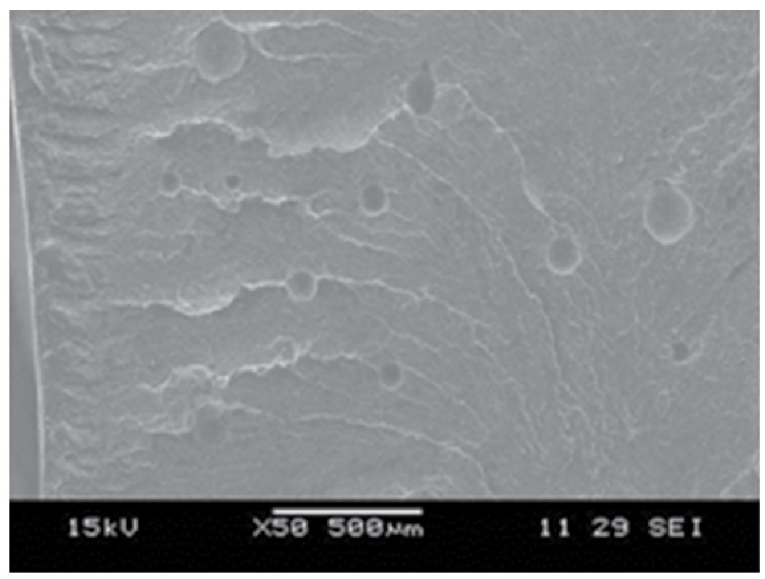

(b)

Figure 3. SEM micrographs of the cross section fractured surface of rotomolded composite: (a) LMDPE02 and (b) LMDPE05, with magnification of $50 \times$.

Table 6. Porosity analysis results of the rotomolded composites.

\begin{tabular}{lcccc}
\hline & \multicolumn{3}{c}{ Cross section Porosity } & \multicolumn{2}{c}{ Surface Porosity } \\
\cline { 2 - 5 } Composite & $\%$ & $\begin{array}{c}\text { Avareage pore } \\
\text { size }(\boldsymbol{\mu m})\end{array}$ & $\begin{array}{c}\text { Pores Quantities } \\
\left(\text { poros } / \mathbf{m m}^{2}\right)\end{array}$ & $\%$ \\
\hline LMDPE00 & - & - & - & 3.4 \\
LMDPE02 & 6.7 & $255 \pm 127$ & 0.27 & 5.4 \\
LMDPE05 & 7.5 & $166 \pm 73$ & 0.72 & 4.3 \\
LMDPE10 & 9.1 & $165 \pm 69$ & 0.90 & 3.5 \\
LMDPE02A & 5.0 & $225 \pm 97$ & 0.27 & 3.4 \\
LMDPE05A & 6.5 & $168 \pm 40$ & 0.69 & 3.2 \\
LMDPE10A & 8.7 & $283 \pm 103$ & 0.30 & 3.1 \\
\hline
\end{tabular}




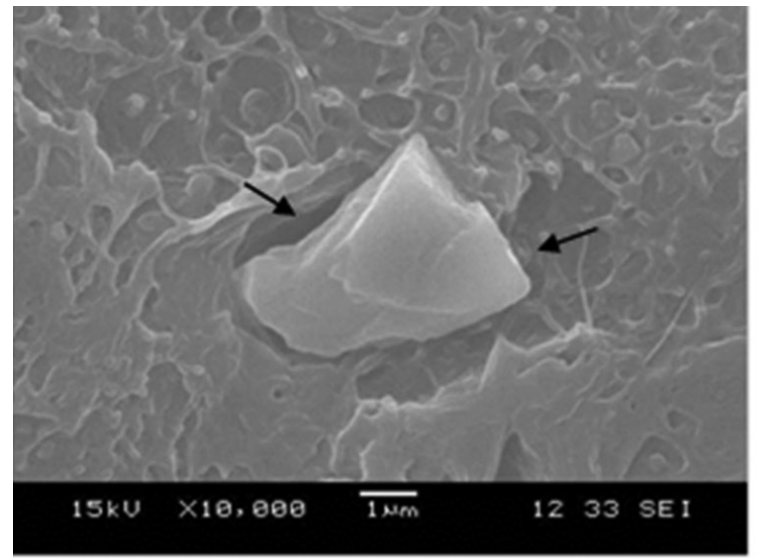

LMDPEO2

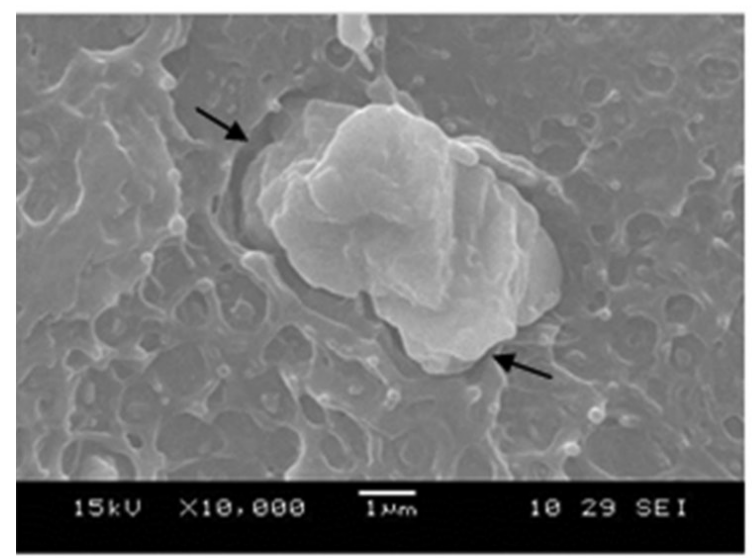

LMDPEOS

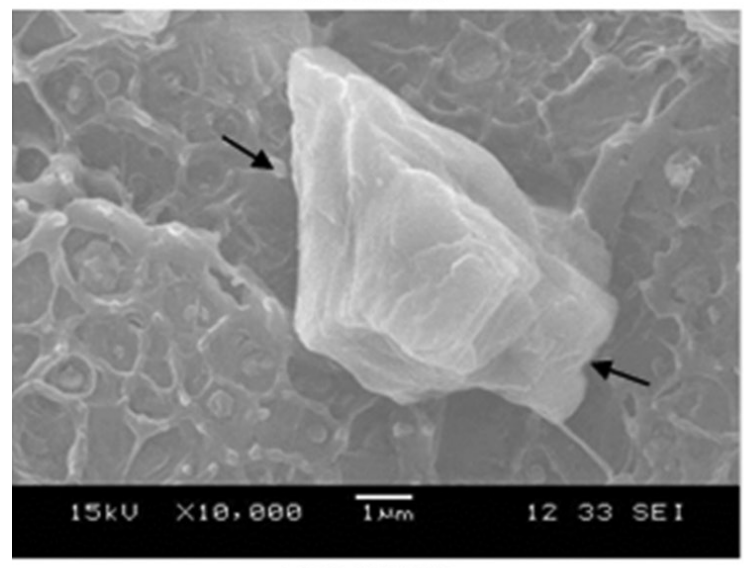

LMD PEPE10

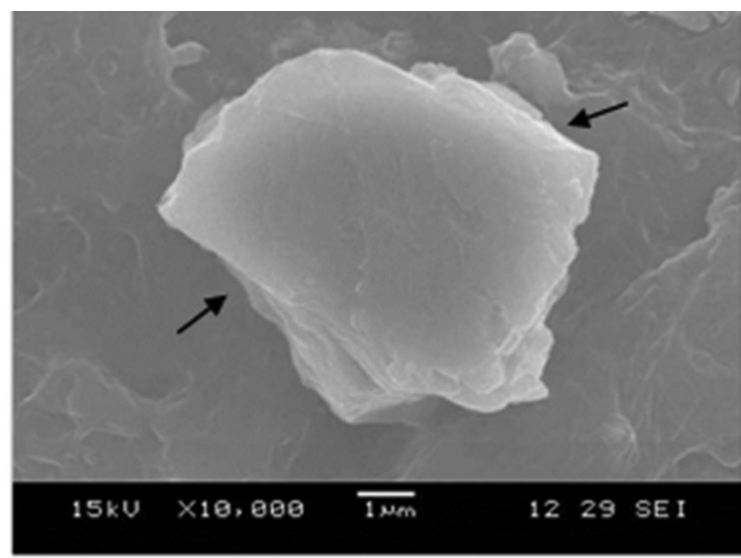

LMDPE02A

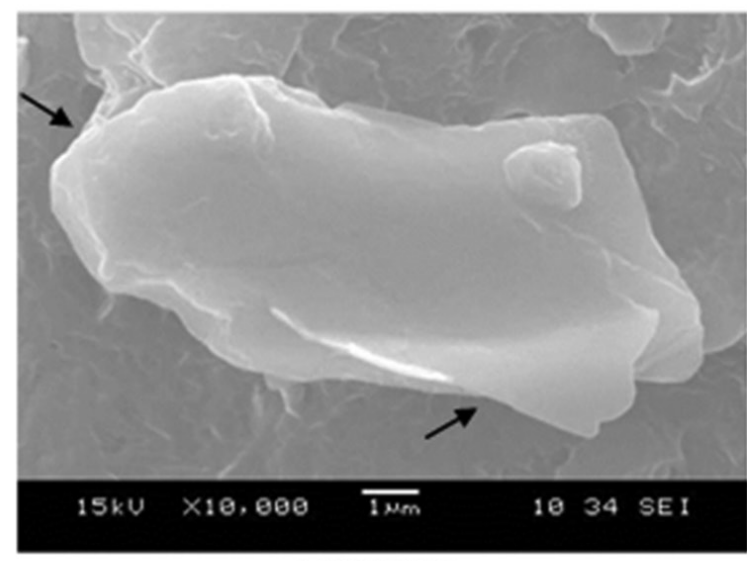

LMDPEOSA

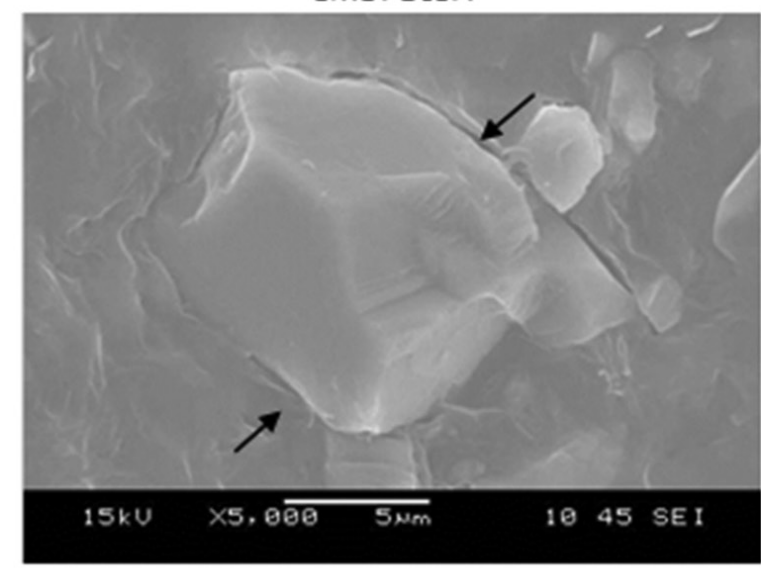

LMDPE1OA

Figure 4. Cryogenic fracture micrographs of the rotomolded composites.

between the $\mathrm{CaCO}_{3}$ particle and LMDPE matrix is visible (indicated by arrows), probably due to the weak interfacial bonding. The same behavior was observed in composites with erucamide, indicated that there is no interaction between the erucamide and $\mathrm{CaCO}_{3}$ and the matrix. Considering the average size of the $\mathrm{CaCO}_{3}$ particles used in this study is about $2.0 \mu \mathrm{m}$ and in the composites (Figure 4) the average size of particle is about 3.0 up to $10.0 \mu \mathrm{m}$, it can be suggested that there are filler agglomeration.
Table 7 summarizes the results for mechanical property tests obtained for all rotomolded composites. It can be seen that the impact strength decreased with the addition of $\mathrm{CaCO}_{3}$ compared with neat LMDPE. The trend of impact resistance decrease may be related to average pore size increase. The pore size could change the tension state of the specimen and change the behavior of the material in impact test. The composites with erucamide showed similar behavior, indicating that the additive does not seem to have 
Table 7. Mechanical properties of rotational molded samples.

\begin{tabular}{lcccc}
\hline \multirow{2}{*}{ Materials } & Impact strenght & Yield strength & Yield deformation & \multicolumn{2}{c}{ Young's Modulus } \\
\cline { 2 - 5 } & $\boldsymbol{K J} / \boldsymbol{m}^{\mathbf{2}}$ & $\mathbf{M P a}$ & $\boldsymbol{\%}$ & $\mathbf{M P a}$ \\
\hline LMDPE00 & $22.5 \pm 0.5$ & $17.6 \pm 0.8$ & $16.0 \pm 1.4$ & $218.6 \pm 14.5$ \\
LMDPE02 & $15.8 \pm 1.9$ & $15.5 \pm 0.6$ & $15.0 \pm 1.0$ & $132.2 \pm 11.1$ \\
LMDPE05 & $18.0 \pm 1.8$ & $15.7 \pm 0.1$ & $14.7 \pm 1.5$ & $159.7 \pm 29.0$ \\
LMDPE10 & $17.4 \pm 2.1$ & $16.1 \pm 0.5$ & $13.7 \pm 1.8$ & $151.8 \pm 30.2$ \\
LMDPE02A & $15.4 \pm 1.9$ & $17.3 \pm 1.3$ & $15.7 \pm 1.2$ & $200.6 \pm 23.7$ \\
LMDPE05A & $19.6 \pm 1.4$ & $16.5 \pm 1.1$ & $14.2 \pm 1.8$ & $162.8 \pm 20.8$ \\
LMDPE10A & $14.6 \pm 1.7$ & $17.4 \pm 0.5$ & $15.0 \pm 1.9$ & $132.9 \pm 19.4$ \\
\hline
\end{tabular}

influenced the impact strength of the rotational molded samples. According to Gogos ${ }^{37}$, the pores must be removed before solidification, because most of the physical properties (impact resistance, tensile strength, elongation, etc.) are affected by the presence of pores. Pick and Harkin-Jones ${ }^{38}$ reported a correlation between the number of voids (pores) and impact strength in a rotational molded sample, and they observed that the greater the number of pores, the lower the impact resistance.

It is possible to observe that LMDPE composites with $\mathrm{CaCO}_{3}$ with and without erucamide do not show any significant difference on yield strength and yield deformation. On the other hand, Young's modulus was reduced by up to $35 \%$ with the addition of $\mathrm{CaCO}_{3}$, behavior also observed with erucamide addition. This decrease can be related with the increase of the porosity. The porosity reduces cross section area and thus decreases the Young's Modulus. It can be also related to the weak interfacial bonding between different phases, as shown in Figure 4 .

\section{Conclusion}

The characterization of the powder samples revealed that the amount of $\mathrm{CaCO}_{3}$ added into LMDPE altered the properties of bulk density, but did not affect the behavior of the dry flow and MFI. However, the addition of erucamide

\section{References}

1. CramezMC, Oliveira MJ and Crawford RJ.Effect of pigmentation on the microstructure and properties of rotationally molded polyethylene. Journal of Materials Science. 1998; 33:48694877. http://dx.doi.org/10.1023/A:1004485825823

2. Liu S-J and Fu K-H. Effect of enhancing fins on the heating/ cooling efficiency of rotational molding and the molded product qualities. Polymer Testing. 2008; 27:209-220. http://dx.doi. org/10.1016/j.polymertesting.2007.10.004

3. Spence AG and Crawford RJ. The Effect of Processing Variables on the Formation and Removal of Bubbles in Rotationally Molded Products Polymer Engineering and Science. 1996; 36:993-1009.

4. Yan WJ, Lin RJT and Bhattacharyya D. Particulate reinforced rotationally moulded polyethylene composites - mixing methods and mechanical properties Composites Science and Technology. 2006; 66:2080-2088 http://dx.doi.org/10.1016/j. compscitech.2005.12.022 as a slip agent showed changes in the dry flow properties and bulk density, suggesting a reduction in the coefficient of friction between the particles and a better packing and no evidences of interaction between the slip agent and $\mathrm{CaCO}_{3}$ was observed.

The porosity analysis in the rotomolded samples showed that the $\mathrm{CaCO}_{3}$ addition increased the porosity. This behavior can be due to the filler hindering the densification of the particles. The analysis of particle size distribution indicated that all powder samples had more than $5 \%$ of particles larger than $500 \mu \mathrm{m}$. This fact also may have contributed to the increased porosity. The erucamide addition showed a slight reduction of the porosity degree in both rotomolded composites, suggesting an improvement in packing particles.

Scanning electron microscopy analyses exhibited the poor adhesion between the $\mathrm{CaCO}_{3}$ particles and the LMDPE matrix, probably due to the weak interfacial bonding between the materials. The porosity and poor adhesion between the filler and matrix can contribute to the decrease in mechanical properties, even though the percentage of the filler added was not significant. The addition of erucamide did not influence the mechanical properties for any samples. To make this project technically feasible it is necessary studying the effect of raise the oven temperature or to increase the heating cycle, so it could possible reduce the porosity and then improve the mechanical properties.

5. Bellehumeur CT, Bisaria MK and Vlachopoulos J. An experimental study and model assessment of polymer sintering Polymer Engineering and Science. 1996; 36:2198. http://dx.doi. org/10.1002/pen.10617

6. Hafsaoui SL, Benziane M and Tcharkhtchi A. Thermal transfer simulation regarding the rotational moulding of polyamide 11 . Journal of Thermal Analysis and Calorimetry. 2013;112:285. http://dx.doi.org/10.1007/s10973-012-2806-4

7. Monzón MD, Bordón P, Benítez AN, Kearns M, Hernández PM and Marrero MD. Global Efficiency of Innovative Rotational Mold Directly Heated by Thermal Fluid. Polymer Engineering and Science. 2012; 1998.

8. Asgarpour M, Bakir F, Khelladi S, Khavandi A and Tcharkhtchi A. 3D Model for Powder Compact Densification in Rotational Molding. Polymer Engineering And Science. 2012; 2033. http:// dx.doi.org/10.1002/pen.23133

9. Torres FG and Aragon CL. Final product testing of rotational moulded natural fibre-reinforced polyethylene Polymer 
Testing. 2006; 25:568-577. http://dx.doi.org/10.1016/j. polymertesting.2006.03.010

10. Planes E, Duchet J, Maazouz A and Gerard JF. Characterization of New Formulations for the Rotational Molding Based on Ethylene-Propylene Copolymer/Graphite Nanocomposites Polymer Engineering and Science. 2008; 48:723. http://dx.doi. org/10.1002/pen.21012

11. Harkin-Jones E and Kanokboriboon AK. Rotational moulding of

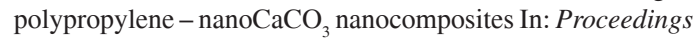
of the Polymer Processing Society PPS-21; 2005, Leipzig. Leipzig; 2005. PMid:16165036.

12. López-Bañuelos RH, Moscoso FJ, Ortega-Gudiño P, Mendizabal E, Rodrigue D and González-Núñez R. Rotational Molding of Polyethylene Composites Based on Agave Fibers. Polymer Engineering and Science. 2012; 2489. http://dx.doi. org/10.1002/pen.23168

13. Rusu G and Rusu E. Anionic Nylon $6 / \mathrm{TiO}_{2}$ Composite Materials: Effects of $\mathrm{TiO}_{2}$ Filler on the Thermal and Mechanical Behavior of the Composites. Polymer Composites. 2012; 1557. http://dx.doi.org/10.1002/pc.22292

14. Yan WJ, Lin RJT and Bhattacharyya D. Mechanical Properties of Rotational Moulded Polyethylene Composites - Experiments and Theories In: 5th Asian-Australian Conference on Composite Materials, China, 2006.

15. González J, Albano C, Ichazo M and Diaz B. Effects of coupling agents on mechanical and morphological behavior of the PP/HDPE blend with two different $\mathrm{CaCO}_{3}$. European Polymer Journal. 2002; 38:2465-2475. http://dx.doi. org/10.1016/S0014-3057(02)00120-9

16. Thio YS, Argon AS, Cohen RE and Weinberg M. Toughening of isotatic polypropylene with $\mathrm{CaCO}_{3}$ particles. Polymer. 2002; 43:3661-3674. http://dx.doi.org/10.1016/ S0032-3861(02)00193-3

17. Dangtungee R, Yun J and Supaphol P. Melt rheology and extrudade swell of calcium carbonate nanoparticle-filled isotatic polypropylene. Polymer Testing. 2005; 24:2-11. http:// dx.doi.org/10.1016/j.polymertesting.2004.08.006

18. Browning R, Lim GT, Moyse A, Sun L and Sue H. Effects of slip agent and talc surface-tratment on the scratch behavior of thermoplastic olefins Polymer Engineering and Science. 2006; 46:601. http://dx.doi.org/10.1002/pen.20507

19. Garrido IQ, Ruiz MFV and Rienda JMB. Fickian diffusion of erucamide (13-cis-docosenamide) in poly(laurolactam) (Nylon 12) (PA-12). Macromolecular Chemistry and Physics. 2000; 201:375. http://dx.doi.org/10.1002/(SICI)15213935(20000201)201:3<375::AID-MACP375>3.0.CO;2-1

20. Chaudhary BI. Thermoplastic compositions for durable goods aplication. U.S. Patent 6.362.270; 2002.

21. Kulikov O, Hornung $\mathrm{K}$ and Wagner M. Novel Processing Additives for Rotational Molding of Polyethylene. Internacional Polymer Processing. 2009; 24:452. http://dx.doi. org/10.3139/217.2296

22. American Society for Testing and Materials - ASTM. ASTM D-1921: Standard Test Methods for Particle Size (Sieve Analysis) of Plastic Materials. Philadelphia: ASTM; 2012.

23. International Organization for Standardization - ISO. ISO 1133: Melt Mass-Flow Rate and Melt Volume-Flow Rate of Thermoplastics. Geneva: ISO; 2006.
24. Crawford RJ and Throne JL. Rotational Molding Technology. Nova York: Plastic Design Library/ William Andrew Publishing; 2002.

25. American Society for Testing and Materials - ASTM. ASTM D-1895: Standard Test Methods for Apparent Density, Bulk Factor, and Pourability of Plastic Materials. Philadelphia: ASTM; 2010.

26. Janimak JJ, Markey L and Stevens GC. Spherulitic banding in metallocene catalysed polyethylene spherulites. Polymer. 2001;42:4675. http://dx.doi.org/10.1016/S00323861(00)00637-6

27. International Organization for Standardization - ISO. ISO 527: Plastics -- Determination of tensile properties -- Part 1: General principles. Geneva: ISO; 2012.

28. International Organization for Standardization - ISO. ISO 180: Determination of Izod impact strength. Geneva: ISO; 2000.

29. Quijada-Garrido I, J. Barrales-Rienda M, Perefia JM and Frutos G. Solubility of erucamide (13-cisdocosenamide) in isotactic poly(propylene) and thermal behaviour of their blends. Polymer. 1997; 38:5125. http://dx.doi.org/10.1016/ S0032-3861(97)0058X-4

30. Leong YW, Abu Bakar MB, Ishak ZAM, Ariffin A and Purkanszky B. Comparison of the mechanical properties and interfacial interactions between talc, kaoli, and calcium carbonate filled polypropylene composites. Journal of Applied Polymer Science. 2004; 91:3315. http://dx.doi.org/10.1002/ app. 13542

31. Leong YW, Ishak ZAM and Ariffin A. Mechanical and thermal properties of talc and calcium carbonate filled polypropylene hybrid composites. Journal of Applied Polymer Science. 2004; 91:3327. http://dx.doi.org/10.1002/app.13543

32. Galera VAV. Simulação da etapa de resfriamento da poliamida no processo de moldagem rotacional (Cooling step simulation of the polyamide in the rotational molding process). [Dissertation]. Ponta Grossa: Universidade Estadual de Ponta Grossa; 2007

33. Narkis M and Rosenzweig N. Polymer Powder Techonoly. Inglaterra: Jonh Wiley \& Sons; 1995.

34. Tiemprateeb S, Hemachandra K and Suwanprateeb J. A comparison of degree of properties enhancement produced by thermal annealing between polyethylene and calcium carbonatepolyethylene composites. Polymer Testing. 2000; 19:329. http:// dx.doi.org/10.1016/S0142-9418(98)00099-3

35. Huang X, Jiang P, Kim C, Duan J and Wang G. Atomic Force Microscopy Analysis of Morphology of Low Density Polyethylene Influenced by Al Nano- and Microparticles. Journal of Applied Polymer Science. 2008; 107:2494. http:// dx.doi.org/10.1002/app.27357

36. Vlachopoulos $\mathrm{J}$ and Takacs E. Recent progress and future challenges in rotational molding. In: Proceedings of the Polymer Processing Society PPS-21, Leipzig, 2005.

37. Gogos G. Bubble removal in rotational molding. Polymer Engineering \& Science. 2004; 44:388. http://dx.doi. org/10.1002/pen.20035

38. Pick LT and Harkin-Jones E. Third Polymer Processing Symposium. Belfast; 2004. p. 259. 